•综述・

\title{
生物银行支撑全球生物多样性研究与保护的实践 与探索
}

杨阳®1,4，张超 ${ }^{2}$, 李保国 $3^{*}$

1. 中国科学院自然科学史研究所, 北京 100190; 2. 中国科学院文献情报中心, 北京 100190; 3. 西北大学生命科学学院, 西安 $710069 ; 4$. 中国新高教集团政策与战略研究中心，昆明 651701

摘要: 要更好地保护全球生物多样性, 人类不仅需要正确认知生物多样性的本质与规律, 还需要审时度势地发展生物多样性 保护的载体, 以此提升生物多样性保护的社会价值和经济效益。本文旨在探讨生物银行对生物多样性研究与保护工作的促进 作用，解决生物银行资源库功能同质化严重、维护困难与急需向更高层次演化等三个主要问题。本文系统回顾了国内外生物 银行的缘起与现状, 通过归纳与演绎的方法介绍了国内外人类基因组银行、动植物种质银行、生态银行与生物多样性银行的 基本特征、运营模式与实践经验。本文的主要观点有: (1)不受时空限制的外向型数据驱动模式是人类基因组银行的主要特征, 本质是技术外包式的共性技术平台，它的最主要的盈利方式是通过收集、存储人体生物样本，并将其整理成为医学研究机构、 制药企业、政府医疗部门需要的医学数据; (2)受特定时空限制的内向型需求驱动模式是动植物种质银行的主要特征, 它更聚 焦代表性动植物及微生物的信息样本普查与测序, 并提倡在中试平台上进行早期小规模的实践活动; (3)自然资本与金融资本 结合的发展模式是生态银行的最大特色，它作为分散零碎的生态资源和产业投资商与运营商之间的中介平台，把环境资源未 破坏但缺乏驱动机制的区域进行人才、技术与资本的快速重组; (4)绑定实体金融机构与科研院所是生物多样性银行的最大特 征, 它以第三方专业的授信与评级机构的形象出现, 其本质是通过环境破坏与环境治理、投入成本与产出收益两个维度的博 亦获得两个高附加值的固定收益及增值收益。文章还提出了生物银行成为全球生物多样性研究与保护的重要载体的建议: (1) 在建设层面要加强顶层设计, (2)在研究层面要理清知识产权权属, (3)在应用层面防止科技伦理的沦丧, (4)在管理层面要建立 通用标准, (5)在产业层面要综合衍生品的设计。

关键词: 生物银行; 发展历史; 实践案例; 运营模式; 未来挑战; 政策建议

杨阳, 张超, 李保国 (2021) 生物银行支撑全球生物多样性研究与保护的实践与探索. 生物多样性, 29, 1425-1433. doi: 10.17520/biods.2021131. Yang Y, Zhang C, Li BG (2021) Practice and exploration of global biodiversity research and protection supported by biobank. Biodiversity Science, 29, 1425-1433. doi: 10.17520/biods.2021131.

\section{Practice and exploration of global biodiversity research and protection supported by biobank}

Yang Yang ${ }^{1,4}$, Chao Zhang ${ }^{2}$, Baoguo $\mathrm{Li}^{3 *}$

1 Institute for the History of Natural Science, Chinese Academy of Sciences, Beijing 100190

2 National Science Library, Chinese Academy of Sciences, Beijing 100190

3 College of Life Sciences, Northwest University, Xi'an 710069

4 Policy and Strategic Research Center of China New Higher Education Group, Kunming 651701

\section{ABSTRACT}

Background \& Aims: To better protect global biodiversity, humans need to correctly understand the nature and laws of biodiversity and to develop plans for biodiversity protection that are situational. Doing so will stimulate the social value and economic benefits of biodiversity protection. The purpose of this paper is to explore the role that biobank has placed in promoting biodiversity research and protection with a goal of solving the following three problems: serious homogenization of biobank resource pool function, difficult maintenance of biobank, and an urgent need to evolve to a

收稿日期: 2021-04-09; 接受日期: 2021-06-11

基金项目: 广东省科学院先导专项(2020GDASYL-20200301003)

* 通讯作者 Author for correspondence. E-mail: baoguoli@nwu.edu.cn 
higher level.

Progresses: We systematically reviewed the origins and current situation of biobank at home and abroad by conducting a literature survey on the basic characteristics, operation mode and practical experiences from the Human Genome Bank (HGB), the Animal and Plant Germplasm Bank, the Ecological Bank, and the Biodiversity Bank. The main feature of the HGB is the data-driven model that is not limited by time and space. The essence of HGB is the common technology platform useful for technology outsourcing. The main way the HGB profits is by collecting and storing human biological samples, and organizing them into medical data important for medical research institutions, pharmaceutical enterprises, and government medical departments. The main feature of the Animal and Plant Germplasm Bank is the introverted demand-driven mode with limitations in time and space. The Animal and Plant Germplasm Bank focuses more on the census and sequencing of representative animals, plant and microbial information samples, and advocates early small-scale practical activities in the pilot platform. The development mode of combining natural capital and financial capital is the biggest feature for the Ecological Bank. As a scattered and fragmented ecological resource and an intermediary platform between industrial investors and operators, the Ecological Bank rapidly reorganizes talents, technology and capital in areas where environmental resources are not destroyed but lack of driving mechanism. The biggest feature of the Biodiversity Bank is that they are bound to real financial institutions and scientific research institutions. The Biodiversity Bank appears as a third-party professional credit and rating agency. The goal of the Biodiversity Bank is to obtain a high value-added fixed income and value-added income from environmental damage and environmental governance.

Prospects: In order to become an important carrier of biodiversity research and protection, we recommend biobank make the following five actions: to strengthen the top-level design at the construction level, to clarify the ownership of intellectual property at the research level, to prevent the decline of science and technology ethics at the application level, to establish common standards at the management level, and to integrate the design of derivatives at the industrial level.

Key words: biobank types; development history; practice cases; operation modes; future challenges; policy suggestions

联合国《生物多样性公约》第十五次缔约方大 会(COP15)于 2021年10月在中国昆明召开, 这是联 合国首次以生态文明为主题召开的全球性会议, 大 会将制定《2020年后全球生物多样性框架》, 是继 “爱知目标” 后, 全球新的10年生物多样性保护行动 计划。要更好地保护全球生物多样性, 人类不仅需 要正确认知生物多样性的本质与规律, 还需要审时 度势地发展生物多样性保护的载体, 以此提升生物 多样性保护的社会价值和经济效益。

生物多样性研究以生物学、生态学和地理学为 学科依托, 开展地球实体生命体(entity group)在形 态、生理、行为等方面的调查与预测。地球实体生 命体的类型一般包括: 与生命遗传相关的生命体多 样性(diversity of life)和有机体多样性(diversity of organisms); 与自然生态过程和物种生境差异性相 关的生态多样性(ecological diversity)、物种多样性 (species diversity)与生境多样性(habitat diversity); 与区域类群分布特征和物种发展相关的分类学多 样性(taxonomic diversity) (马克平, 1993)。

遗传多样性专注实体生命体的遗传结构与变
异的探究，往往与核酸的理化特征息息相关，并衍 生出以“基因库”为特征的研究载体。生境多样性专 注动物、植物、昆虫群落的组织水平, 聚焦物种演 化与维持机制的规律, 并衍生出以“种质库”为特征 的研究载体。生态过程的多样性专注气候、地貌、 土壤、水质、空气等环境变量的影响因素、变化过 程与治理手段, 并衍生出以“生态库”为特征的研究 载体。分类学多样性专注不同周期内同一地区可视 物种的损耗状况、速率及成因, 并衍生出以“指标 库” 为特征的研究载体 (McKenney \& Kleserker, 2010)。

在全球可持续发展的大背景下, 全球生物多样 性的研究与保护工作发生了极大的变化, 从依靠国 家出资转向依靠社会资本, 其模式也由任务驱动转 向市场驱动, 其形态由研究属性更强的“库”转向市 场属性更强的“银行”。至此, “基因库”变为“生物组 学银行”, “种质库”变为“生物种质银行”, “生态库” 变为“生态银行”, “指标库”变为“生物多样性评估银 行”。因此, 完善生物银行的结构框架、理顺生物银 行的运作机制在当下具有理论与实践双重意义。 


\section{1 国内外生物银行发展概述}

生物银行早在2009年就被美国《时代》杂志评 为 “改变世界的十大构想”之一, 其最大的功能就是 系统和前瞻性地存储了大量稀有基因组或生物组 织样本, 目前已成为全球个性化组学研究和组学产 业化的支柱, 引领着全球生物医药及生态保护行业 的走向。

\section{1 国外生物银行的缘起与现状}

生物银行并非以传统商业银行的现金、贵金 属、债券、股票等金融资产的储备与管理能力为根 基, 而是以细胞、血液、组织等生物样本的采集、 保存、研究、应用的水平为核心竞争力。生物银行 以“生物样本库”为基础业务形态, 最早起源于1949 年美国海军样本库的建设, 发展于1987年美国国家 肿瘤生物样本库 (Cooperation Human Tissue Network, CHTN)的实践, 兴起于20世纪末信息科学 管理与生命测序技术相结合的广泛应用, 成熟于 21 世纪世界各国有关生命医学、生态环保的战略部署, 先后产生了国际生物和环境资源库协会 (International Society for Biological and Environmental Repositories, ISBER)、泛欧洲生物样 本库与生物分子资源研究平台 (Biobanking and Biomolecular Resources Research Infrastructure, BBMRI)、中东和非洲生物银行学会(EMEA Society for Biological Bank, ESBB)、英国生物银行 (UK Biobank)、卢森堡联合生物样本库 (Integrated BioBank of Luxembourg, IBBL)及卡罗林斯卡医 学院样本库(KI Biobank)等全球知名的生物银行载 体(Garcia et al, 2018)。

近年来, 全球生物样本库市场的需求量每年以 约 30\%的速度增长, 市场规模向万亿美元进发, 西 方发达国家与一些新兴发展中国家开始加快生物 银行的建设步伐。以欧洲生物银行建设与发展为例, 欧盟框架计划(Framework Programme, FP) 是欧洲最 大的研究与创新支持计划, 被欧盟视为保持全球知 识经济领导地位、增强欧洲全球技术竞争力的重要 财政工具。当前正在实施的FP8成为欧盟有史以来 最大的研究资助计划, 在过去的7年(2014-2020)有 800亿欧元投入 “地平线2020项目” (Horizon 2020), 该项目旨在支持欧盟卓越科学计划、竞争性行业崛 起以及应对社会挑战(social chalenges, SC) 三个议
题。其中, 应对社会挑战第一款侧重于“健康、人口 变化和社会福祉” (SC1), 致力于生物医学研究中的 热点主题，其预算高达74.72亿欧元(Kinkorová \& Topolčan, 2018)。而BBMRI自受到FP7资助后, 于 FP8 (2021-)再次成为SC1项目优先级资助的对象; 7年间, BBMRI运营和开发了泛欧分布式研究基础 设施, 促进了欧盟内部生物资源和相关数据的综 合利用，支持了全球其他生物银行高质量的生物 分子和生物医学的研究 (Argudo \& Domènech, 2020)。

\section{2 国内生物银行的缘起与现状}

中国生物银行的雉形源于1994年中国科学院 建设的中华民族永生细胞库。从1996年开始, 先后 兴建了国家级的肿瘤组织库、脐带血造血干细胞 库、重大疾病临床与样本资源库、人群队列样本库、 免疫细胞库等(Chen et al, 2015)。最具有代表性的类 生物银行资源库是成立于1996年的北京肿瘤医院 临床肿瘤研究所的临床肿瘤库, 重点收集人类常见 肿瘤组织标本和肿瘤邻近组织, 并把这些组织血液 中分离出来的血清和血浆进行二次收储, 在10年内 就获得了 50 万份样本数据, 为中国生物银行资源库 建设提供了良好的实践经验(Cheng et al, 2013)。受 其经验的启发, 类生物银行资源库在新千年后呈现 爆发式增长的态势, 其中名气较大的是2001年成立 的华南肿瘤学国家重点实验室, 这是中国最大的肿 瘤库之一, 其特色是除了常规的组织、血液与细胞 等样本的收集外, 还系统地将蛋白质、DNA、RNA 进行收储, 目前拥有的样本已超过 100 万份。与之组 织形式类似且具有代表性的省域类生物银行还包 括: 天津肿瘤组织库 (TMUCIH Cancer Biobank, 2004年)、浙江癌症医院肿瘤库(2007年)、江苏启东 市肝癌研究所生物库(2011年)等(Gan et al, 2015)。

“十一五”期间, 随着国家863计划“常见重大疾 病全基因组关联分析和药物基因组学研究” 的布局, 中国类生物银行资源库开始转向市场价值更高的 重大疾病遗传病因的探索与重大疾病靶向药的研 制。至此, 兼顾社会效益与经济效应的中国生物银 行的倠形开始显现, 其中较为著名的商业化生物银 行当属全球最大的基因测序服务中心“诺禾致源” 以 及由“华大基因”领导的深圳国家基因库(简称国家 基因库)等基因组学共性技术载体(Song et al, 2015)。而真正将生物样本库与社会资本进行融合并 
开发利用是国家“十二五”规划时期，这源于新一代 测序技术的基因组学成为国家“十二五”科技规划的 重点研发内容, 而生物医药又成为中国战略新兴产 业中最受地方政府青崃的热门行业。“十三五”期间, 在中国生物银行样本库建设经验与样本积累的基 础上, 一些区域性的生物银行联盟开始出现。如 2019年，在创投资源丰富的深圳，由中国国家疾控 中心(CCDC)牵头14家具有生物样本库建设与管理 资质的单位组建了粤港澳大湾区科技基础资源共 享联盟, 为中国国家级生物银行建设以及世界级别 的动植物、微生物生物样本库、组学数据库建设奠 定了坚实的基础(乐晶晶等, 2020)。

\section{3 国内外生物银行发展的共性症结}

国内外生物银行面临的共性症结有3个方面: (1) 类生物银行资源库功能同质化严重。类生物银行基 本都利用了医院这种区域性或专业性的垄断地位 的机构来建立自己的疾病库, 其主要用途为科学研 究, 缺乏有效的商业化运作。(2)生物银行的内涵和 外延急需拓展。当前, 生物银行的分类高度聚焦在 以人类为核心的组学研究与组学产业化领域, 忽略 了 “生物圈” 中所有组学本底数据的开发价值与利用 潜力, 这也客观反映出生物银行要实现可持续发展 任重而道远的现状。(3)类生物银行的维护难度较 大。类生物银行非营利性或营利水平较低的资源库 需要政府的长效资金支持, 以此缓解其研究周期短 和建设周期长之间的矛盾; 政府一旦缩减资金支持 力度, 类生物银行的前期积累很容易 “烂尾”。因此, 生物银行产业链布局与产业系统完善依然需要对 国内外不同种类、典型性生物银行的基本特征与运
营模式展开进一步归纳与总结。

\section{国内外生物银行的种类，特征与运营模王}

如将生物银行的资源库视为经营性资产，那么 生物银行可被定义为一个商业概念性十足的、人与 自然环境和谐发展的新兴产业化载体, 它以传统银 行的资产评估与信贷授信业务为依托，引入了人与 动植物基因测序、生物(生态)资源开发利用、濒危 (或区域特色)物种资源保育、生物多样性监测与预 警等4类技术型业务模块，同时兼顾了绿色金融与 绿色扶贫的基本属性。其中, 人类与动植物基因测 序目前是生物银行常见的业务形态，衍生出“人类 基因组银行” 和 “动植物种质银行”两种业务模式, 构建了生物银行发展的底层技术, 兼顾了以生物 (生态)资源开发利用以及以濒危(或区域特色)物种 资源保育为主营业务的“生态银行”建设。同时, 随 着全球城市化进程的推进, 绿色可持续发展理念深 入人心, 一种“泛”生物银行上且与商业资本绑定的 生物多样性调查、评估、监测与预警业务悄然兴起, “生物多样性银行”建设开始走上历史舞台。

\section{1 人类基因组银行的运营模式与实践案例}

不受时空限制的外向型数据驱动模式是人类 基因组银行的主要特征, 本质是技术外包式的共性 技术平台, 其最主要的盈利方式是通过收集、存储 人体生物样本以及相关的临床资料(如组织、血液、 细胞、DNA、器官等), 并将其整理成医学研究机构、 制药企业、政府医疗部门急需的医学数据, 减少中 试实验、产品研发中所消耗的调研成本与时间成本, 为甲方提供支撑区域性健康战略的精准靶向方案。

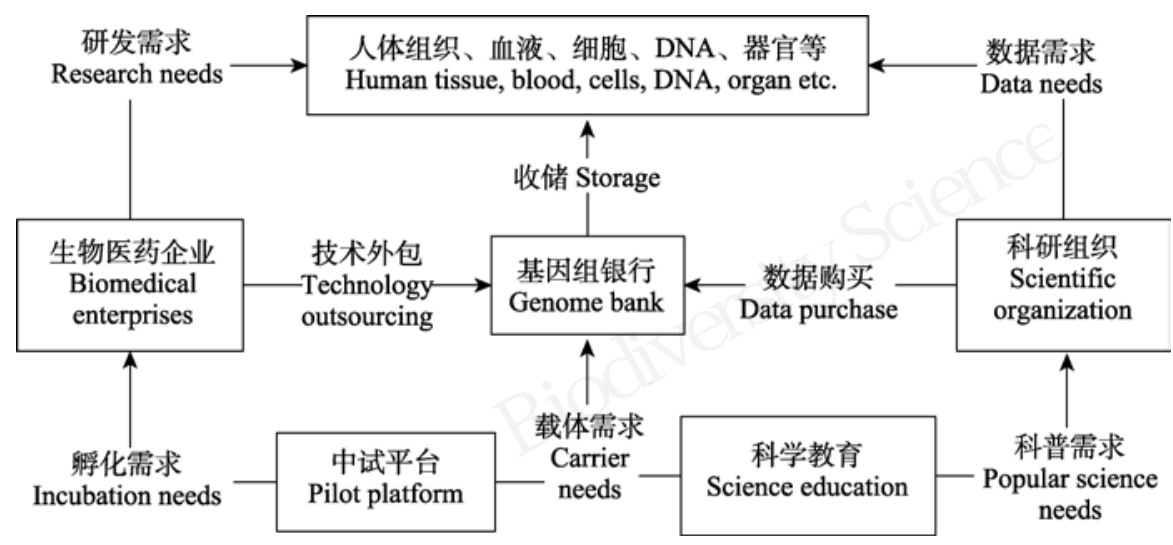

图1 人类基因组银行运营模式

Fig. 1 Operation mode of human genome bank 
此外, 人类基因组银行还承载着两个附属功能: (1) 成为产教型科研组织有关生命科学基础教育的实 践载体; (2)成为生物医药企业技术成果的中试场地 (图1)。从实践来看, 虽然国外的人类基因组银行起 步较早, 但国内相关领域的建设并未被拉开差距。

国外最知名的生物银行有英国生物银行 (UK Biobank)、德国莱比锡生物银行(Leipzig Medical Biobank)与美国梅奥诊所生物银行 (Mayo Clinic Biobank)。英国生物银行是迄今世界上种类最全、 规模最大的人类信息资源库, 其生物样本仓储存了 超过 1,500 万种生物信息样本, 其图像扫描中心还 收录了脑部、心血管、骨骼等高清晰度的典型性图 像样本, 这些数据为科研人员在遗传学与流行性病 学两个领域提供了崭新的思考方式和研究方向, 为 全球人类健康奠定了重要基础(Bycroft et al, 2018); 德国莱比锡生物银行的优势在于其先进的储存技 术, 储存生物样本的精细化分类水平高, 涉及 $-80^{\circ}$ 的核酸样本、 $-130^{\circ}$ 的细胞、蛋白质样本和 $-150^{\circ}$ 的 血细胞样本等, 同时其生物样本提取的物理空间可 始终保持在 $-110^{\circ}$, 这使其样本数据质量极高、可靠 性极强, 目前已为全球350项重要医学研究项目提 供了数据支撑(Baber \& Hummel, 2019)。梅奥诊所生 物银行是依托全球著名的美国梅奥诊所 (Mayo Clinic)雄厚的科研实力与丰富的临床经验建立而成, 它是美国政府“精准医学计划”的重要组成部分, 美 国政府在其建设初期就资助了 1.3 亿美元, 因而它 最大的优势来源于政府主导的样本采集与资源交 换、临床研究与数据共享网络, 这个开放式网络涉 及全美4,000家医院(其中覆盖全美就医规模最大的 前20家医院), 这无疑推进了其关联医院的研究实 力与诊治效率(Olson et al, 2019)。

国内北、中、南三个区域各有一个代表性的生 物银行, 分别是北京中关村生物银行、上海张江生 物银行以及深圳华大基因科技有限公司(简称华大 基因)。北京中关村生物银行于2016年年底成立并于 2017年正式运营, 是国内首家以“生物银行”命名的 民营组织, 致力于用大数据的方法治疗罕见病, 通 过收集罕见病医学样本并与全球罕见病医学平台 进行数据共享和交换, 旨在解决罕见病研究样本 小、组学数据缺乏的困境, 但目前仍在发展的初期 阶段, 仅获得天使轮投资(师毅, 2019)。上海张江生 物银行是由张江区管委会立项、国资科技型企业牵
头承担的张江科学城重要项目, 于2017年投入运营, 比中关村生物银行投入规模更大、智能化水平更 高、综合研究能力更强。除基础的生物样本收集和 储存功能以外, 它还建立了生物样本信息模拟的实 验室, 并即将建成全国首个虚拟生物样本库(叶扬 等, 2017)。华大基因虽然从未以生物银行命名, 但 却拥有与 “生物银行” 业务板块较为一致的产业链体 系, 目前也是国内从事人类基因库科技研发与应用 的品牌企业, 其业务开展极为多元化, 不仅涉及罕 见疾病、动植物、微生物全领域基础测序, 还为甲 方提供了如基因组研究、高精度医学仪器制造(测序 试剂和影像平台)等高技术供应链服务, 近年来保 持了较好的盈利水平(苟尤钊和林菲, 2015)。

\section{2 动植物种质银行的运营模式与实践案例}

受特定时空限制的内向型需求驱动模式是动 植物种质银行的主要特征, 与人类基因组银行不同, 它更聚焦代表性动植物及微生物的信息样本普查 与测序, 并提倡在中试平台上进行早期小规模的实 践活动。从甲方客户来看, 动植物种质银行的服务 对象多来自于特定的区域政府, 旨在帮助他们解决 生态资源衰退所引发的区域性物种丧失以及外来 物种恶性入侵造成的生物多样性失衡等问题。从运 营特征来看, 动植物种质银行种质样本的存储环境 要求 $\left(-20^{\circ}\right)$ 远低于人类基因组银行, 但其收集(普查) 手段往往通过主动的区域生态本底数据的调查来 实现, 这比人类基因组银行随机输入样本数据更为 可靠和更有针对性。从技术输出来看, 动植物种质 银行更偏向于应用研究, 即专注特定区域种质样本 生存条件、遗传机制、培育改良、救助保育、识别 监控等方面的技术储备与更新迭代, 为区域绿色可 持续发展提供坚实的技术保障(图2)。

国内外动物种质银行的典型案例并不多, 而植 物种质银行的实践则较为丰富, 如美国的国家植物 种质系统(National Plant Germplasm System, NPGS)、英国邱园(Gardens Kew)的“千年种子库”、 澳大利亚植物银行(Plant Bank)等。国外目前最具有 影响力的动植物综合性种质银行为日本国家农业 科学研究所的基因银行(NIAS Gene-bank), 它是日 本1985年国家植物、微生物和动物遗传资源的收集 保存计划的重要载体, 旨在解决日本生态问题背景 下的食品安全风险, 自成立至今已完成了对日本主 要经济作物DNA样本的全测序, 收录样本 91 万余 


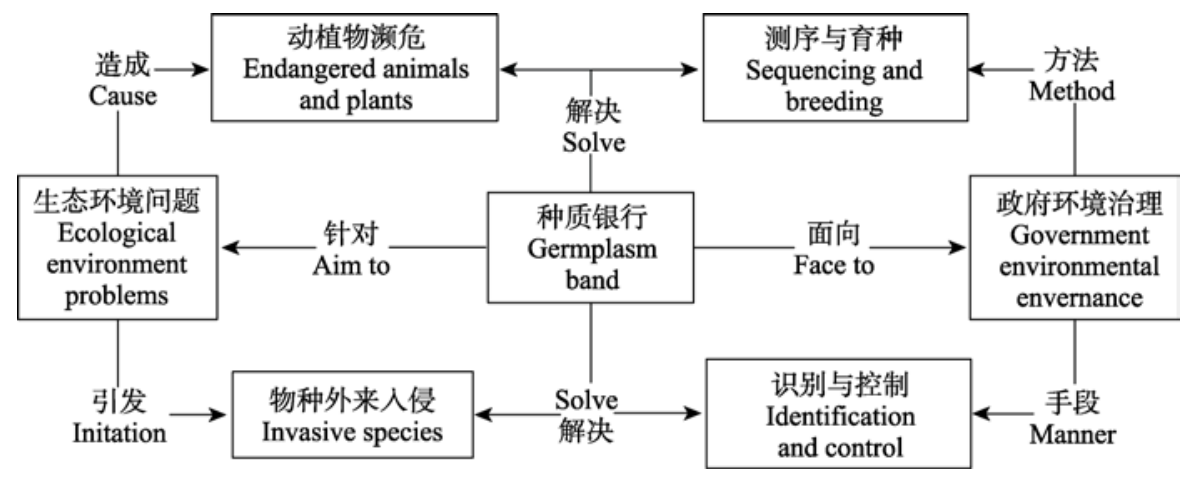

图2 种质银行运营模式

Fig. 2 Operation mode of germ plasm bank

份, 在此基础上培育水稻、小麦、大麦、大豆、果 树、蔬菜等新品种22.4万余份; 同时, 日本农业科学 院(Nation Institute Agrobiological Science, NIAS)已 保存日本常见的植物病原及食品微生物(细菌、真 菌、酵母和病毒等) DNA 3.3万余份; 此外, NIAS还 保存了全日本濒危动物DNA约1,900份。基于可持续 发展议题, NIAS积极向全球提供部分热带与亚热带 经济作物的样本数据, 甲方只需在线花费很少的费 用就可以获得(Takahashi et al, 2005)。国内目前最具 有影响力的种质银行是中国西南野生生物种质资 源库，它是全亚洲最大的野生生物种质资源的“诺 亚方舟”, 保存了中国野生植物种子、重要野生植物 的离体材料和DNA材料、重要动物的细胞器和重要 微生物菌株等遗传材料, 至今已收录各类种质资源 21,666种225,522份/株(条)。同时, 中国西南野生生 物种质资源库还是中国重要的种质研究基地, 已建 成智能植物志核心元素(DNA条形码库), 收录了中 国近万种重要植物的12万个DNA条形码及其物种 信息。此外, 中国西南野生生物种质资源库还是中 国重要的科学培训基地, 迄今已对近2,000名各级 自然保护区的工作人员进行了生物多样性保护理 论和种子采集保藏技术的培训(周桔等, 2021)。

\section{3 生态银行的运营模式与实践案例}

生态银行与技术要求较高的人类基因组银行 和动植物种质银行不同, 它是一种新兴的优质生态 资源流转的金融驱动方式, 自然资本与金融资本结 合的发展模式是其最大特色。作为分散零碎的生态 资源和产业投资商与运营商之间的中介平台, 生态 银行针对环境资源未破坏、“碳中和”能力较强但缺 乏驱动机制的未开发/欠开发区域进行人才、技术与 资本的快速重组。从运营方式上看, 生态银行在区
域政府的监督下, 通过租赁、入股、托管、赎买等 多种方式将碎片化生态资源的集中收储和规模化 整治, 转换成连片优质高效的资源包, 并委托运营 商进行经营。从盈利手段上看, 生态银行具备了绿 色金融的倠形(图3): 一方面, 通过对未开发土地的 收储、作价与抵押换得银行贷款, 贷款资金及土地 资源(银行以股权形式参股)二次投入到具有市场潜 质的环保项目中, 以提升地区商业环境吸引力, 保 障环保项目稳定的盈利水平; 另一方面, 通过对已 开发土地的实际损耗进行评估, 并向非环保项目的 受益方进行授信, 然后根据授信额度提取一定比例 的项目收益, 该收益用于设立补偿已损坏土地的新 项目, 以此保障地区生态环境的可持续发展。

生态银行的最大优势是提升了生态资源的承 载力、使用与转化效率, 同时缓解了政府投入压力、 降低了政府债务风险。生态银行是中国特色社会主 义建设中的实践产物, 在助力中国脱贫攻坚、乡村 振兴方面得到了很好的应用。如福建南平市率先进 行了生态银行的试点, 将区域优质生态资源与社会 资本结合形成了“森林生态银行” (补偿项目)、“文化 生态银行” “建盏生态银行” “古厝生态银行”等多种 运作模式, 先后打造出属于自己的产品与文化IP, 成功带动南平市旅游业营收同比增长21.3\% (958亿, 2019年), 这也成为“绿水青山”向“金山银山”转变的 实践典型(刘耕源等, 2021)。

\section{4 生物多样性银行的运营模式与实践案例}

生物多样性银行是绿色金融的主要形态, 主要 运用在经济发达的地区, 它与生态银行最大的不同 就是绑定了实体金融机构与科研院所, 其评估对象 往往是政府主导的工程类项目, 且评估范围较生态 银行更广。作为第三方专业的授信与评级机构, 生 


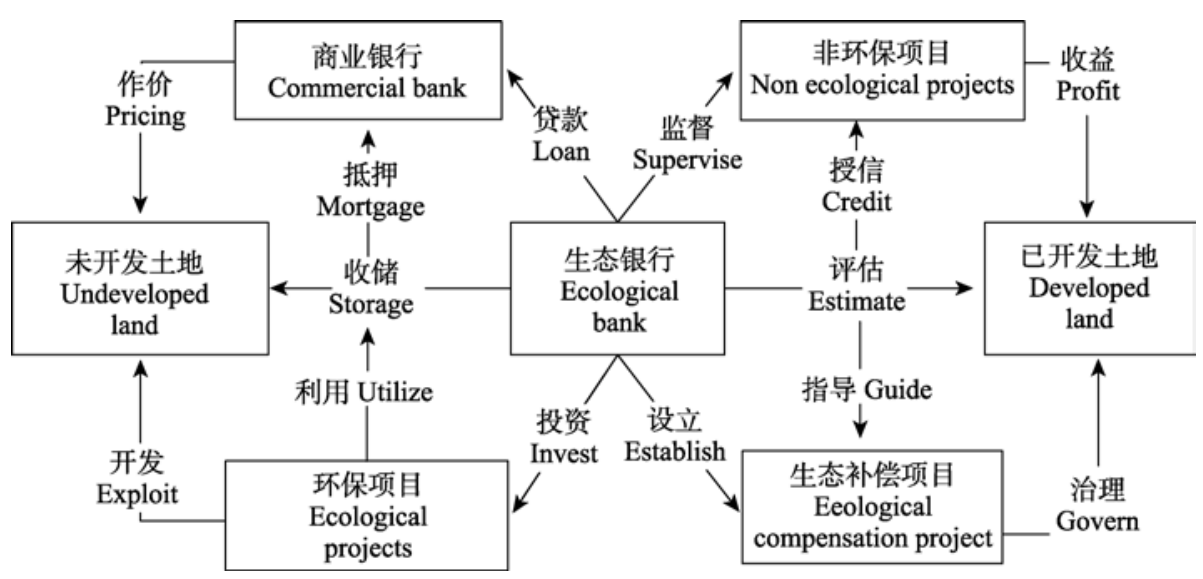

图3 生态银行运营模式

Fig. 3 Operation mode of ecological bank

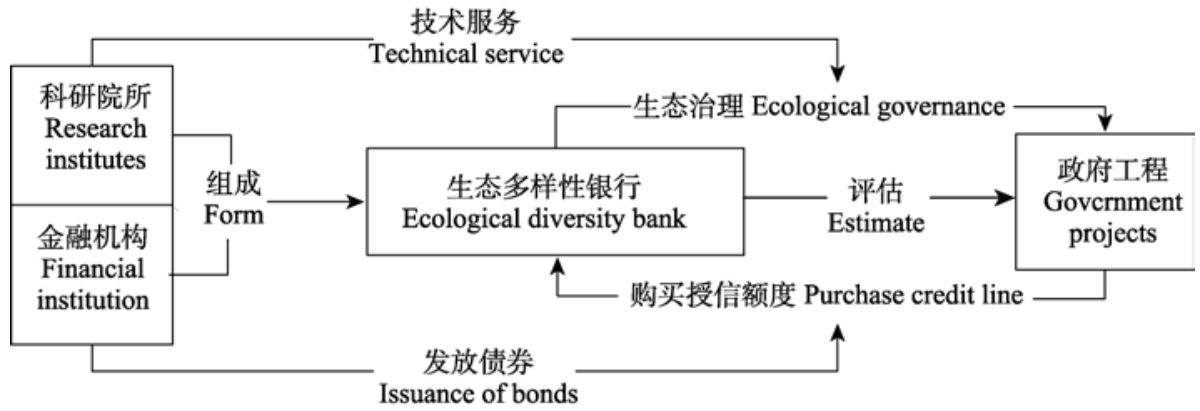

图4 生态多样性银行运营模式

Fig. 4 Operation mode of ecological diversity bank

物多样性银行通过对某一个区域政府主导的生态 资源消耗型项目进行评估与授信获得盈利, 其本质 是通过环境破坏与环境治理、投入成本与产出收益 两个维度的博峦获得两个高附加值的固定收益及 增值收益, 即项目环评中的咨询评价收益、利用企 业购买授信额度和所缴纳保证金的投资收益，上述 两项收益又在担保、补偿、恢复、拓展区域生物多 样性的基础活动中得到了二次收益的机会。其运营 模式如图4所示。

目前全球大约有108个国家涉及生物多样性银 行的核心业务, 在咨询评估中多以“无净损失” (又 称零净损失, 指通过生态补偿使生态损耗的总面积 不减少)机制为主要评价方法。从实际运用上看, 这 种机制的优劣势非常明显, 优势在于易快速置换出 金融资本, 劣势在于在环境保护中的作用不够理 想。从美国保护区银行、澳大利亚新南威尔士生物 银行两个较为知名的生物多样性银行对美国河流 和湿地的生态系统、欧洲潮汐泥滩和池塘、澳大利 亚森林的研究案例上看, 湿地生态系统生物多样性
补偿易实现中和(零损); 而对林地则不可能，因为 其生态结构发生了不可预测/难以预测的改变 (Kumaraswamy \& Udayakumar, 2011)。从生物多样 性银行提供的监测手段上看，通过GIS遥感技术对 测评区林地、水源、土壤宏观图像按区域损耗，并 配合“无净损失”的评价机制进行作价补偿是现行惯 用的方法，但这种方法也不利于观察生态环境的微 观变化及延续过程。因此, 未来将生物多样性银行 与种质银行进行业务融合有可能成为赢得区域政 府、资本市场青睐的有效途径(Bull et al, 2018)。

\section{3 生物银行未来的机遇与挑战}

全球生物银行要成为生物多样性研究与保护 的重要载体还需要克服五大共性问题，这也将成为 全球生物银行发展的机遇与挑战。

(1)建设层面的顶层设计。由于生物银行在建设 层面的准入门槛较高, 在人力、结构、关系、资本 方面都需要大规模、持续性的投入，因此在建设初 期就需要进行顶层设计，一般涉及政府治理水平、 
资源供给能力、区域发展战略的匹配与论证，区域 技术人才、政策红利、产业资本的引入与导流，区 域生物安全、信息安全与债务安全的承载力评估与 风险防控等三项主要工作的规划制订。

(2)研究层面上的知识产权权属。由于生物银行 主要以样本测序共性技术及数据分析通用技术的 供给为盈利模式, 在样本使用中涉及生物银行、政 府科研机构、企业研发部门等多方主体, 其不同领域 的产出成果将面临知识产权保护范围、权利归属、 利益分享等重要议题, 这些问题的解决是激励生物 银行发展、为其营造良好发展环境的现实需求。

(3)应用层面的科技伦理。由于对生物样本进行 基因测序及储存是生物银行的主要工作, 因此最容 易触碰动植物细胞系编辑、制造与改造基因编辑等 违反道德伦理的红线, 特别是在研究人员职业素养 缺失、基因编辑市场隐性需求巨大、政府监管滞后 与失灵的三重压力冲击下, 生物银行有可能反而成 为扰乱社会稳定、危及人类健康、破坏生态安全的 助推器。

(4)管理层面的通用标准。以中国为例, 尽管已 出台《中国生物样本库与建立指南》《生物样本库 质量和能力通用要求》等多个生物银行建设与行动 指南，但针对不同区域、不同种类、不同业务的实 施细则依然难产, 导致生物样本在采集、处理、注 释、储存、审查、包装、运输、使用、监督、推广 与销毁等多个环节难以形成通用标准, 造成管理无 序、低水平、低效率重复现象时有发生。

(5)产业层面综合衍生品的设计。由于生物银行 形式与种类的多样性, 其未来发展需要具备将现有 单一线性业务模块进行整合的能力, 使之演变成集 生物信息数据战略储备和综合性科学研究、核心技 术外包研发及共性技术平台配套服务、区域濒危生 物种群的治理方案、区域生物多样性预测模型及防 控系统的开发、生态开发中的评估、授信、担保与 投资于一体的综合性商业服务载体。

\section{生物银行发展的政策建议}

根据生物银行所面临的五大共性问题, 本文提 出了对应的政策建议:

(1)加强生物银行的顶层设计, 以面向国家生 物安全重大战略需求与生物产业创新发展为导向, 制定集生物保存技术、生物组学与功能学技术、分
子生物实验技术于一体的技术发展路线图, 完善生 物银行间的技术合作机制与人才培养模式, 打破阻 碍生物银行间资源共享、互换的壁垒, 为国家生物 安全提供重要的技术、数据与载体支撑。同时, 将 生物银行纳入战略性新兴产业生物产业的子目录 中, 利用政府引导基金与社会资本相结合的方式合 理制定生物银行的经营业务与发展规模, 形成强有 力的造血机制, 保障生物银行的可持续发展。

(2)形成国家生物银行知识产权保护的新格局, 具体措施包括: (i) 设立生物银行知识产权法院, 加 快以生物遗传资源为核心的知识产权立法建设, 明 确生物银行资源权属与利益分享的基本权利; (ii)研 判与梳理生物遗传资源核心技术清单, 编制生物遗 传资源使用与交换手册, 鼓励区域间成立生物银行 自治联合体，共同维护、监督生物遗传资源的研发、 使用与交易规范; (iii)充分借鉴国外生物银行知识 产权防御性保护措施, 做好相关情报资料的检索与 收集工作, 最大范围地探索生物遗传资源的专有 性、特殊性与可保护性。

(3)从技术层面与制度层面出发, 建立政府、社 会与生物银行共同参与管理的生物安全伦理体系。 在技术层面, 要利用大数据、人工智能、区块链等 新兴技术对生物遗传资源的使用过程进行存证, 对 生物遗传资源的滥用或缪用进行准确的追溯与严 厉的处罚, 保障生物银行遗传资源在研究、开发与 应用中的合理使用; 在制度层面, 对生物遗传资源 进行分类分级, 对高级别资源的使用施行严格的备 案制度; 同时, 还要建立生物银行从业人员的道德 审查的动态机制, 并向从业者提供常态化的行为准 则培训, 使他们树立正确的科技伦理观。

(4)成立国家和地区生物银行标准化委员会, 针对生物银行的管理与服务体系建立生物银行ISO 90000 系列的达标与资质认证标准, 进一步探索生 物银行的建设与验收、从业人员的审查与培训、生 物仪器的操作与维护、库存资源的储存与销毁、生 物资源样本的交易与运输的标准化模式; 针对生物 银行的研发与应用体系完善生物银行 ISO 20387的 国际通用标准, 进一步规范生物遗传数据的采集与 存证、生物遗传技术的研究与中试、生物产品开发 的条件与要求等标准化流程, 为生物银行走向标准 化、规划化道路奠定坚实的基础。

(5)推进生物银行产业领域的细分工作、加快生 
物银行产业应用版图的规划设计。重点培育以生物 组学、合成生物学、测序科学为核心的产业技术, 探 索以战略性生物资源储备、生物多样性大数据分 析、精准医学技术服务为基础的产业路径, 聚焦生 物银行不同类型产品的研发、中试、应用与推广的 全过程, 对具有市场潜力的技术与产品提供融资担 保与融资服务; 同时，在资本优势较为明显的地区， 以项目为驱动对生物银行的业务进行主动重塑, 以 增强生物银行产业的内循环动力, 形成生物银行产 业链与供应链稳定的双螺旋结构。

\section{ORCID}

杨阳 (D) https://orcid.org/0000-0003-0193-4609

\section{参考文献}

Argudo P, Domènech M (2020) The reconfiguration of biobanks in Europe under the BBMRI-ERIC framework: Towards global sharing nodes? Life Sciences Society and Policy, 16, 1-15.

Baber R, Hummel M (2019) Nussbeck and Cornelia Specht. Biopreservation and Biobanking, 17, 372-374.

Bull JW, Brauneder K, Darbi M, Teeffelen AV, Quetier F, Brooks SE, Dunnett S, Strange N (2018) Data transparency regarding the implementation of European 'no net loss' biodiversity policies. Biological Conservation, 218, 64-72.

Bycroft C, Freeman C, Petkova D, Band G, Elliott LT, Sharp K, Motyer A, Vukcevic D, Delaneau O, Connell JO, Cortes A, Welsh S, Young A, Effingham M, McVean G, Leslie S, Allen N, Donnelly P, Marchini J (2018) The UK biobank resource with deep phenotyping and genomic data. Nature, 562, 203-209.

Chen H, Chan B, Joly Y (2015) Privacy and biobanking in China: A case of policy in transition. The Journal of Law, Medicine \& Ethics, 43, 726-742.

Cheng LE, Shi C, Xian W, Li Q, Yong Z (2013) Chinese biobanks: Present and future. Genetics Research, 95, 157164.

Gan YX, Wang HY, Song YT, Fan JL (2015) Chinese biobanking initiatives. Biopreservation and Biobanking, 13, 4-7.

Garcia M, Downs J, Russell A (2018) Impact of biobanks on research outcomes in rare diseases: A systematic review. Orphanet Journal of Rare Disease, 13, 202-215.

Gou YZ, Lin F (2015) A study on the new type of research institutes based on the perspective of innovation value chain. Science \& Technology Progress and Policy, 32(2), 8-13. (in Chinese with English abstract) [苟尤钊, 林菲 (2015) 基于 创新价值链视角的新型科研机构研究. 科技进步与对策, 32(2), 8-13.]

Kinkorová J, Topolčan O (2018) Biobanks in Horizon 2020: Sustainability and attractive perspectives. EPMA Journal, 9, 345-353.
Kumaraswamy S, Udayakumar M (2011) Biodiversity banking: A strategic conservation mechanism. Biodiversity and Conservation, 20, 1155-1165.

Le JJ, Zhou XX, Yao HS, Liu SJ, Ma YH (2020) Living biobank: Current development and ethical considerations. Scientia Sinica (Vitae), 50, 1464-1474. (in Chinese) [乐晶 晶, 周学迅, 姚海嵩, 刘世建, 马永慧 (2020) 生物样本 活库发展现状及伦理问题探讨. 中国科学: 生命科学, 50, 1464-1474.]

Liu GY, Yan NY, Yang Q, Zhao Y (2021) Research on eco-bank operation mechanism and localtransformation: A case study. Natural Resource Economics of China, 34(2), 4-13, 48. (in Chinese with English abstract) [刘耕源, 颜宁 聿, 杨青, 赵勇 (2021) 生态银行运行机制与本土化改造 研究: 案例实证. 中国国土资源经济, 34(2), 4-13, 48.]

Ma KP (1993) On the concept of biodiversity. Chinese Biodiversity, 1, 20-22. (in Chinese) [马克平 (1993) 试论 生物多样性的概念. 生物多样性, 1, 20-22.]

McKenney BA, Kleserker JM (2010) Policy development for biodiversity offsets: A review of offset frameworks. Environmental Management, 45, 165-176.

Olson J, Ryu E, Hathcock MA, Gupta R, Bublitz JT, Takahashi PY, Bielinshi S, Sauver JL, Meagher K, Sharp RR, Thibodeau SN, Cicek M, Cerhan JR (2019) Characteristics and utilisation of the Mayo Clinic Biobank, a clinic-based prospective collection in the USA: Cohort profile. BMJ Open, 9, e032707.

Shi Y (2019) Zhongguancun "Biobank”: The hope of storage future. Zhongguancun, (4), 16-19. (in Chinese) [师毅 (2019) 中关村 “生物银行”: 存储未来的希望. 中关村, (4), 16-19.]

Song Y, Wang P, Yu G, Gan R (2015) Turning point: Biobanking in China and the future of translational research. Biopreservation and Biobanking, 13, 2-3.

Takahashi H, Tsudzuki M, Sasaki O, Niikura J, Inoue-Murayama M, Minezawa M (2005) A chicken linkage map based on microsatellite markers genotyped on a Japanese Large Game and White Leghorn cross. Animal Genetics, 36, 463-467.

Ye Y, Zhang KH, Gao HJ (2017) Biobank: A new model of intensive biological sample bank. Practical Journal of Organ Transplantation (Electronic Version), 5, 415-416, 398. (in Chinese) [叶扬, 张可浩, 郜恒骏 (2017) 生物银行: 集约 化生物样本库新模式. 实用器官移植电子杂志, 5, 415-416, 398.]

Zhou J, Yang M, Wen XY, Li N, Ren H (2021) Strengthen ex situ conservation of plants and promote protection and utilization of plant resources. Bulletin of Chinese Academy of Sciences, 36, 417-424. (in Chinese with English abstract) [周桔, 杨明, 文香英, 李楠, 任海 (2021) 加强植物迁地 保护, 促进植物资源保护和利用. 中国科学院院刊, 36, 417-424.]

(责任编委: 徐靖 责任编辑: 黄祥忠) 